\title{
In-Hospital Outcomes of Patients with Acute Decompensated Heart Failure and Cirrhosis: An Analysis of the National Inpatient Sample
}

\author{
Yaser S. Khalid (D) · Debashis Reja • Neethi R. Dasu • Herman P. Suga • \\ Kirti N. Dasu • Lucy M. Joo
}

Received: May 12, 2020 / Published online: June 8, 2020

(C) The Author(s) 2020

\begin{abstract}
Introduction: Heart failure increases morbidity and mortality in patients admitted for cirrhosis. Our objective was to determine if patients with acute decompensated heart failure (ADHF) and cirrhosis would have increased mortality, hospital length of stay (LOS), and total hospital charges compared to patients with only ADHF. There is also a paucity of data regarding the influence of gender, race, ethnicity, insurance, and cirrhosis-related complications on mortality, hospital length of stay, and total hospitalization charges. In this study, we aim to identify
\end{abstract}

Digital features To view digital features for this article go to https://doi.org/10.6084/m9.figshare.12383729.

Y. S. Khalid ( $₫) \cdot$ N. R. Dasu - H. P. Suga

Division of Internal Medicine, Rowan University

School of Medicine at Jefferson Health System,

Stratford, NJ, USA

e-mail: ysksorosh1990@gmail.com

D. Reja

Division of Internal Medicine, Rutgers Robert Wood Johnson Medical School, New Brunswick, NJ, USA

K. N. Dasu

Division of Biology, Syracuse University, Syracuse, NY, USA

L. M. Joo

Division of Gastroenterology, Jefferson Health New Jersey, New Jersey, USA risk factors in a national population cohort from 2016.

Methods: All patients above 18 years old with cirrhosis and ADHF admitted in 2016 were identified from the Nationwide Inpatient Sample (NIS). Multivariate regression analysis was used to estimate the odds ratio of in-hospital mortality, average length of stay (LOS), and total hospital charges after adjusting for the following factors: age, gender, race, Charlson and Elixhauser scores, primary insurance payer status, hospital type, hospital bed size, hospital region, and hospital teaching status. Statistical analysis was performed by using the survey procedures function in the statistical analysis system (SAS) software. Statistical significance was defined by the two-sided t-test with a $p$ value $<0.05$.

Results: The overall sample contained 363,050 patients. A total of 355,455 patients were admitted with ADHF and $2 \%$ of these patients had concomitant cirrhosis $(n=7595)$ in 2016 . The total mortality rate was $3.4 \%$, hospital LOS was 6.6 days (with a median of 6.5 days), and the mean total hospital charge was $\$ 63,120.20$. Patients with both ADHF and cirrhosis compared to patients without ADHF had increased mortality, hospital LOS, and cirrhosis-related complications.

Conclusions: As the incidence and prevalence of ADHF and cirrhosis increases worldwide, we urge the medical community to increase surveillance of patients with both diseases and 
perform rigorous cardiovascular risk assessments as well to improve patient outcomes.

Keywords: Cirrhosis; Heart failure mortality; Hospital charges; Length of stay; NIS

\section{Key Summary Points}

Why carry out this study?

Acute decompensated heart failure (ADHF) is a leading cause of inpatient admissions in the United States; it accounts for more than 1 million admissions as the primary diagnosis alone and almost 39.2 billion dollars of inpatient costs yearly.

However, there is a paucity of data regarding the influence of sex, race, insurance, and cirrhosis-related complications on mortality, hospital length of stay, and total hospitalization charges for patients with ADHF and cirrhosis.

In this study, we aim to identify risk factors in a national population cohort admitted in 2016.

\section{What was learned from the study?}

For 355,455 patients with ADHF in 2016, propensity-matched and multivariate logistic regression analysis of 7595 patients with both ADHF and cirrhosis showed that mortality was almost two times higher in patients with ADHF and cirrhosis compared to patients without cirrhosis $(p<0.001)$, mean hospital length of stay was 1.2 times higher in patients with ADHF and cirrhosis $(p<0.001)$, but the mean total charge of hospitalization was not statistically significant.

It is of paramount importance that clinicians, administrators, and patients themselves are aware of the toll these two diseases can take if the relationship is not identified early in the disease processes.

\section{INTRODUCTION}

ADHF is a leading cause of inpatient hospital admissions in the United States. This disease entity accounts for more than 1 million admissions as the primary diagnosis, with almost 39.2 billion dollars of inpatient hospital costs yearly [1]. Among the 6 million Americans with heart failure (HF), the hospitalization rate is 18 per 1000 patients over the age of 64 . This leads to over 700,000 patients that are hospitalized each year [2]. Although there has been considerable progress in managing patients with $\mathrm{HF}$, the rate of hospitalizations continues to rise each year [3]. More than half of the patients admitted with HF have multiple comorbidities during the last two decades [3]. Identifying which comorbidities further increase hospital costs and readmissions could possibly help in better managing patients with HF and thus decreasing the burden on our healthcare system. One of these comorbidities, cirrhosis, is a fatal condition that has a high likelihood of progressing to end-stage liver failure.

The treatment and management of cirrhosis has greatly improved in recent years, yet the economic burden has remained high over time. The overall healthcare costs of liver cirrhosis encompass high direct costs (medications and hospitalization costs) totaling 2.5 billion dollars and high indirect costs (loss of work productivity and reduced health-related quality of life) totaling 10.6 million dollars yearly [4]. This patient population is extremely vulnerable to any external or internal stress on the body as well [3].

ADHF and cirrhosis have also been previously linked together. They were defined as a single disease process, "cirrhotic cardiomyopathy," in the 1960s. There have been very few studies on cirrhotic cardiomyopathy [5]. Cardiac dysfunction in patients with cirrhosis is due to impaired contractility secondary to stress, diastolic dysfunction, and electrical abnormalities manifesting as prolonged QT intervals $[4,5]$. Our objective was to determine if patients with both ADHF from all etiologies and cirrhosis would have increased mortality, 
hospital LOS, and total hospital charges compared to patients with only ADHF. There is also a paucity of data regarding the influence of sex, race, insurance, and cirrhosis-related complications on mortality, hospital LOS, and total hospitalization charges. In this study, we aim to identify risk factors in a national population cohort admitted in 2016.

\section{METHODS}

\section{Study Population}

The NIS database covers approximately 7 million inpatient hospital stays in the United States annually. The database stratifies all-payer inpatient data by hospital region and type of insurance [6]. The NIS is updated yearly to generate a sample that can represent approximately onefifth of all United States hospital patient data. Then, patient data is de-identified and organized by primary and secondary diagnoses. The NIS database provides demographic information, primary and secondary intervention data, cost-related data, and hospital LOS data for each unique hospitalization. This large nationwide population sample has been utilized to analyze regional and hospital-level patterns, quality of care, procedure-related patterns, and trends that would otherwise be impossible to analyze at a local or center-based study level. For our study, data was extracted to study patients with a diagnosis of both ADHF from any cause and all etiologies of cirrhosis. The data we utilized was obtained from the NIS, a Healthcare Cost and Utilization Project (HCUP) database, for the year 2016. Ethics committee approval was not required because the NIS data used in this study was fully de-identified and therefore was considered exempt from institutional review board approval. The datasets are publicly available in the NIS 2016 data repository at https://www. hcup-us.ahrq.gov/databases.jsp.

\section{Design}

We performed a retrospective, observational cohort study using the NIS database. Our study identified 363,050 patients that were discharged in 2016, older than 18 years of age, and with any diagnostic code containing "cirrhosis" and "acute decompensated heart failure." To identify the diagnoses, we used the following International Classification of Diseases, 10th Revision, Clinical Modification (ICD-10-CM) codes for cirrhosis: alcoholic cirrhosis of the liver without ascites (K70.30), alcoholic cirrhosis of liver with ascites (K70.31), cirrhosis (K74.60), biliary cirrhosis (K74.5), unspecified cirrhosis of liver (K74.60), and other cirrhosis of the liver (K74.69). ADHF was defined as I50.21. Cirrhosis-related complications were extracted with the following codes: ascites (R18.8), variceal bleeding (I85. 01), hepatorenal syndrome (HRS) (K76.7), portal hypertension (K76.6), and hepatic encephalopathy (G93.4).

\section{Primary Outcome and Variables}

The primary outcome was to compare the difference in mortality, hospital LOS, and total hospital charges among the group with ADHF and cirrhosis compared to ADHF only. Further multivariate logistic regression analysis was performed to understand possible differences in complications across the two groups. The complications were the following: HRS, ascites, variceal bleeding, hepatic encephalopathy, and portal hypertension.

\section{Statistical Analyses}

The patient information and data were analyzed using Stata version 16 (Stata Corp, College Station, TX, USA) and SAS version 9.4 (SAS Institute Inc. Cary, NC, USA). The study population was generated from primary unit clusters that are representative of the diagnoses we studied. Then, we used patient-level and hospital-level weights provided in the dataset to generate national population estimate samples. Univariate and multivariate comparisons were performed utilizing Chi-squared analyses and Student's $t$ tests. Both fixed and random effects logistic models were used to evaluate predictors of mortality for patients with ADHF and cirrhosis. Odds ratios, confidence intervals, and 
$p$ values were reported for all the outcomes. The statistical significance level was set at a $p$ value of $<0.05$. Propensity matched scoring was used for the analysis to produce matched patient populations of ADHF and cirrhosis and ADHF to minimize confounders.

To prevent the production of uneven outlier weights and to achieve a sample that would be closest to the weighted medians of the NIS sample, we analyzed continuous variables within the upper and lower interquartile ranges and categorical variables were treated as weighted proportions. The cost-to-charge data from the HCUP were used to deconstruct costrelated data from the NIS database.

We generated propensity scores to compare our two analysis groups (ADHF with cirrhosis and ADHF without cirrhosis) using a multivariate logistic regression that was based on risk factors and demographic data from the NIS database. A matching algorithm was used to balance covariates across our study groups through one-to-one matches. This was based on the propensity scores we generated. We adjusted the propensity score balancing properties. The two propensity-matched group outcomes were evaluated using the average bootstrapped treatment effects method.

\section{RESULTS}

The baseline characteristics of our patient population for both cohorts are listed in Table 1. A total of 363,050 patient hospitalizations were identified during the study period of 2016, which consisted of 7580 patients with ADHF and cirrhosis and 355,455 with only ADHF. After propensity matching, there were 7595 patients for both populations. There were 2865 women $(37.8 \%) ; 65.3 \%$ of the patients were white. The mean age was 66.4 years. Charlson comorbidity index (CCI) scores were $>3(92 \%)$ and Elixhauser scores were $>4(88.7 \%)$ for most of our patient cohort, indicating significant disease burden at baseline.

Both patient cohorts had many similarities at baseline. Most of the patients had Medicare insurance (65.2\%). Hospital characteristics were the following: $45.6 \%$ of the hospitals were in the South, $65.4 \%$ of the hospitals were urban teaching centers, and $53.9 \%$ of the hospitals were large; $37.6 \%$ of the patients had an income less than $\$ 24,999$.

We identified differences between the cohorts and then directly compared and analyzed both cohorts. Mortality was higher for patients with ADHF and cirrhosis (3.4\%) compared to patients with only cirrhosis (2.0\%). Total hospital charges were $\$ 63,120$ and $\$ 60,210$, respectively, but the hospital charges were not statistically relevant $(p<0.063)$. Additionally, patients with both conditions had much higher rates of ascites (32.2 and 1.6\%, respectively), variceal bleeding (9.5 and 1.9\%, respectively), and portal hypertension (13.9 and $0.2 \%$, respectively) compared to patients with only ADHF.

Then, propensity-matched multivariate logistic regression analysis was used to remove confounders and showed that mortality was almost two times higher in patients with ADHF and cirrhosis compared to patients without cirrhosis $(p<0.001)$. Mean hospital LOS was 1.2 times higher in patients with ADHF and cirrhosis $(p<0.001)$, but the mean total charge of hospitalization was not statistically significant. There was a higher incidence of complications for patients with ADHF and cirrhosis that was statistically significant $(p<0.001)$ for all of the complications with the following odds ratios: 24.84 times higher for HRS, 30.2 times higher for ascites, 5.57 times higher for variceal bleeding, $\quad 13.85$ times higher for hepatic encephalopathy, and 73.15 times higher for portal hypertension.

Finally, propensity-matched univariate logistic regression revealed that Hispanic patients with ADHF and cirrhosis had $42 \%$ less mortality compared to patients with only ADHF $(p<0.018)$ and higher total hospitalization charges of $\$ 19,072.59(p<0.001)$. Asians and Pacific Islanders with ADHF and cirrhosis had the greatest increase in total hospital charges of $\$ 25,518.01$ compared to patients without cirrhosis $(p<0.0003)$.

Patients with ADHF and cirrhosis who had Medicare insurance had an increased hospital LOS (OR 1.58, 0.68-2.48, $p<0.0006$ ) and 
Table 1 Baseline characteristics

\begin{tabular}{|c|c|c|c|c|}
\hline \multicolumn{5}{|c|}{ ADHF with/without cirrhosis } \\
\hline Characteristics & ADHF with cirrhosis & $\begin{array}{l}\text { ADHF without } \\
\text { cirrhosis }\end{array}$ & Total & $p$ value \\
\hline \multicolumn{5}{|l|}{ No (\%) of patients } \\
\hline Original sample & $7595(2.0 \%)$ & $355,455(98.0 \%)$ & $363,050(100.0 \%)$ & \\
\hline $\begin{array}{l}\text { After propensity score } \\
\text { matching }\end{array}$ & $7580(50.0 \%)$ & $7580(50.0 \%)$ & $15,160(100.0 \%)$ & \\
\hline Women, $n,(\%)$ & $2865(37.8 \%)$ & $2867(37.8 \%)$ & $5732(37.8 \%)$ & 0.97 \\
\hline \multicolumn{5}{|l|}{ Race/ethnicity, $n,(\%)$} \\
\hline White & $4952(65.3 \%)$ & $5040(66.5 \%)$ & 9992 (65.9\%) & 0.0012 \\
\hline Black & $1242(16.4 \%)$ & $1297(17.1 \%)$ & $2539(16.7 \%)$ & \\
\hline Hispanic & $963(12.7 \%)$ & $883(11.6 \%)$ & $1846(12.2 \%)$ & \\
\hline Asian or Pacific Islander & $153(2.0 \%)$ & $134(1.8 \%)$ & $287(1.9 \%)$ & \\
\hline Native American & $61(0.8 \%)$ & $27(0.4 \%)$ & $88(0.6 \%)$ & \\
\hline Other & $209(2.8 \%)$ & $199(2.6 \%)$ & $408(2.7 \%)$ & \\
\hline \multicolumn{5}{|l|}{ Age } \\
\hline Mean (SD) & $66.4(11.6)$ & $66.7(12.6)$ & $66.5(12.1)$ & 0.11 \\
\hline $\begin{array}{l}\text { Median }(25 \text { th }-75 \text { th } \\
\text { percentile) }\end{array}$ & $66.0(58.0,75.0)$ & $67.0(58.0,76.0)$ & $66.0(58.0,75.0)$ & \\
\hline \multicolumn{5}{|l|}{ CCI score, $n,(\%)$} \\
\hline 0 & 0 & 0 & 0 & \\
\hline 1 & $1(0.0 \%)$ & $841(11.1 \%)$ & $842(5.6 \%)$ & $<0.0001$ \\
\hline 2 & $603(8.0 \%)$ & $1905(25.1 \%)$ & $2508(16.5 \%)$ & \\
\hline$>3$ & $6976(92.0 \%)$ & $4834(63.8 \%)$ & $11,810(77.9 \%)$ & \\
\hline \multicolumn{5}{|l|}{ Elixhauser score, $n,(\%)$} \\
\hline 0 & 0 & $142(1.9 \%)$ & $142(0.9 \%)$ & $<0.0001$ \\
\hline $1-3$ & $853(11.3 \%)$ & $3033(40.0 \%)$ & $3886(25.6 \%)$ & \\
\hline$>4$ & $6727(88.7 \%)$ & $4405(58.1 \%)$ & $11,132(73.4 \%)$ & \\
\hline \multicolumn{5}{|l|}{ Insurance type, $n,(\%)$} \\
\hline Medicare & $4942(65.2 \%)$ & $4840(63.9 \%)$ & $9782(64.5 \%)$ & $<0.0001$ \\
\hline Medicaid & $1243(16.4 \%)$ & $976(12.9 \%)$ & $2219(14.6 \%)$ & \\
\hline Private & $967(12.8 \%)$ & $1271(16.8 \%)$ & $2238(14.8 \%)$ & \\
\hline Self-pay & $245(3.2 \%)$ & $278(3.7 \%)$ & $523(3.4 \%)$ & \\
\hline No charge & $14(0.2 \%)$ & $27(0.4 \%)$ & $41(0.3 \%)$ & \\
\hline
\end{tabular}


Table 1 continued

ADHF with/without cirrhosis

\begin{tabular}{|c|c|c|c|c|}
\hline Characteristics & ADHF with cirrhosis & $\begin{array}{l}\text { ADHF without } \\
\text { cirrhosis }\end{array}$ & Total & $p$ value \\
\hline Other & $169(2.2 \%)$ & $188(2.5 \%)$ & $357(2.4 \%)$ & \\
\hline \multicolumn{5}{|l|}{ Hospital region } \\
\hline Northeast & $1430(18.9 \%)$ & $1452(19.2 \%)$ & $2882(19.0 \%)$ & \multirow[t]{4}{*}{0.47} \\
\hline Midwest & $1298(17.1 \%)$ & $1306(17.2 \%)$ & $2604(17.2 \%)$ & \\
\hline South & $3459(45.6 \%)$ & $3503(46.2 \%)$ & $6962(45.9 \%)$ & \\
\hline West & $1393(18.4 \%)$ & $1319(17.4 \%)$ & $2712(17.9 \%)$ & \\
\hline \multicolumn{5}{|c|}{ Hospital location/teaching status } \\
\hline Rural & $641(8.5 \%)$ & $673(8.9 \%)$ & $1314(8.7 \%)$ & \multirow[t]{3}{*}{0.089} \\
\hline Urban non-teaching & $1980(26.1 \%)$ & $1866(24.6 \%)$ & $3846(25.4 \%)$ & \\
\hline Urban teaching & $4959(65.4 \%)$ & $5041(66.5 \%)$ & $10,000(66.0 \%)$ & \\
\hline \multicolumn{5}{|l|}{ Hospital bed size } \\
\hline Small & $1293(17.1 \%)$ & $1259(16.6 \%)$ & $2552(16.8 \%)$ & \multirow[t]{3}{*}{0.31} \\
\hline Medium & $2201(29.0 \%)$ & $2140(28.2 \%)$ & $4341(28.6 \%)$ & \\
\hline Large & $4086(53.9 \%)$ & $4181(55.2 \%)$ & $8267(54.5 \%)$ & \\
\hline \multicolumn{5}{|l|}{ Household income } \\
\hline$\$ 1-24,999$ & $2847(37.6 \%)$ & $2909(38.4 \%)$ & $5756(38.0 \%)$ & \multirow[t]{4}{*}{0.72} \\
\hline$\$ 25,000-34,999$ & $1930(25.5 \%)$ & $1881(24.8 \%)$ & $3811(25.1 \%)$ & \\
\hline$\$ 35,000-44,999$ & $1653(21.8 \%)$ & $1645(21.7 \%)$ & $3298(21.8 \%)$ & \\
\hline 45,000 or more & $1150(15.2 \%)$ & $1145(15.1 \%)$ & $2295(15.1 \%)$ & \\
\hline Mortality $(n, \%)$ & $258(3.4 \%)$ & $154(2.0 \%)$ & $412(2.7 \%)$ & $<0.0001$ \\
\hline \multicolumn{5}{|l|}{ Length of stay, days } \\
\hline Mean (SD) & $6.6(6.5)$ & $5.4(6.0)$ & $6.0(6.3)$ & \multirow[t]{2}{*}{$<0.0001$} \\
\hline $\begin{array}{l}\text { Median }(25 \text { th }-75 \text { th } \\
\text { percentile) }\end{array}$ & $5.0(3.0,8.0)$ & $4.0(2.0,7.0)$ & $4.0(3.0,7.0)$ & \\
\hline \multicolumn{5}{|c|}{ Total charge of hospitalization } \\
\hline Mean (SD) & $63,120.2(86,257.3)$ & $60,210.1(105,491.5)$ & $61,665.0(96,364.0)$ & \multirow[t]{2}{*}{0.063} \\
\hline $\begin{array}{l}\text { Median }(25 \text { th }-75 \text { th } \\
\text { percentile) }\end{array}$ & $\begin{array}{c}38,297.0(21,708.0 \\
71,332.0)\end{array}$ & $\begin{array}{c}32,586.0(18,378.0 \\
64,409.5)\end{array}$ & $\begin{array}{c}35,278.0(19,780.0 \\
67,942.0)\end{array}$ & \\
\hline Hepatorenal syndrome & $121(1.6 \%)$ & $5(0.1 \%)$ & $126(0.8 \%)$ & $<0.0001$ \\
\hline Ascites & $2438(32.2 \%)$ & $120(1.6 \%)$ & $2558(16.9 \%)$ & $<0.0001$ \\
\hline Variceal bleeding & $717(9.5 \%)$ & $141(1.9 \%)$ & $858(5.7 \%)$ & $<0.0001$ \\
\hline
\end{tabular}


Table 1 continued

\begin{tabular}{llllc}
\hline ADHF with/without cirrhosis & & & \\
\hline Characteristics & ADHF with cirrhosis & $\begin{array}{l}\text { ADHF without } \\
\text { cirrhosis }\end{array}$ & Total & $\boldsymbol{p}$ value \\
\hline Hepatic encephalopathy & $14(0.2 \%)$ & $1(0.0 \%)$ & $15(0.1 \%)$ & 0.0008 \\
Portal hypertension & $1051(13.9 \%)$ & $17(0.2 \%)$ & $1068(7.0 \%)$ & $<0.0001$ \\
\hline
\end{tabular}

decreased total hospital charges by $-\$ 6902.92$ $(p<0.028)$.

Only HRS and ascites uniformly increased mortality $[3.38$ times $(p<0.00008)$ and 1.46 times, respectively $(p<0.0051)]$. Both complications increased hospital LOS by 2.35 times $(p<0.0001)$ and 1.29 times $(0.0001)$, respectively. Finally, HRS and ascites increased total hospital charges by $\$ 21,547.6(p<0.0063)$ and $\$ 5376.21(p<0.012)$ respectively for patients with both ADHF and cirrhosis compared to patients without cirrhosis. Hepatic encephalopathy increased mortality by 4.73 times $(p<0.047)$ and total hospital charges by $\$ 511,113.29(p<0.025)$ but it did not affect hospital LOS. The presence of portal hypertension decreased mortality by $35 \%(p<0.039)$ and hospital LOS by $24 \%(p<0.0007)$ for our patient population.

\section{DISCUSSION}

This is the first large, retrospective population cohort study of 7595 propensity matched patients with ADHF and cirrhosis that used a sample of 363,050 patients from the NIS database. Our study is the first that analyzes patients with both ADHF and cirrhosis compared to patients with only ADHF to assess the impact on patient mortality, hospital LOS, and total hospital charges. Our findings suggest that patients with ADHF and cirrhosis had a two-fold increase in mortality and 1.2-fold increase in hospital LOS, except for the Hispanic population. We used multivariate logistic regression and propensity matched analysis to remove confounders.
The statistically significant findings in our study were as follows: independent positive predictors of mortality were cirrhosis-related complications (specifically HRS, ascites, hepatic encephalopathy), while independent negative predictors were Hispanic ethnicity and portal hypertension. Independent positive predictors of hospital LOS were Medicare insurance, hepatorenal syndrome, and ascites, whereas the only independent negative predictor was portal hypertension. For total hospital charges, independent positive predictors were Hispanic ethnicity and Asian/Pacific Islander race as well as cirrhosis-related complications (HRS, ascites, hepatic encephalopathy) illustrated in Tables 2 and 3; the only independent negative predictor was Medicare insurance.

HF is a growing public health problem due to increasing mortality rates and rising health care costs due to comorbidities like cirrhosis that require prolonged hospitalization and treatment with diuretics $[7,8]$. The common underlying pathophysiological mechanisms of ADHF and cirrhosis may explain why our patient cohort had a higher rate of mortality and a longer hospital LOS [9-11]. At the beginning of the disease cycle, patients with HF have a lowered cardiac output, whereas patients with cirrhosis undergo systemic arterial vasodilation that increases cardiac output. Both disease processes instigate arterial underfilling, which in turn stimulates a sympathetic response that releases non-osmotic vasopressin. This results in an increased sympathetic tone and renal $\beta$ adrenergic stimulation, and, as a result of this change in tonicity, activates the renin-angiotensin aldosterone system (RAAS) [11-13]. Ultimately, sodium and water retention occurs as a result of these processes and presents as 
Table 2 Outcomes of ADHF with and without cirrhosis

\begin{tabular}{llllc}
\hline & $\begin{array}{l}\text { ADHF with } \\
\text { cirrhosis }\end{array}$ & $\begin{array}{l}\text { ADHF without } \\
\text { cirrhosis }\end{array}$ & $\begin{array}{l}\text { Multivariate beta/OR } \\
(\mathbf{9 5 \% ~ C I})\end{array}$ & $\boldsymbol{p}$ value \\
\hline Mortality $(n, \%)$ & $258(3.4 \%)$ & $154(2.0 \%)$ & $\mathbf{1 . 7 8}(\mathbf{1 . 4 5}, \mathbf{2 . 1 8})$ & $<0.0001$ \\
Mean length of stay, days (mean, SD) & $6.6(6.5)$ & $5.4(6.0)$ & $\mathbf{1 . 2}(\mathbf{1}, \mathbf{1 . 4})$ & $<0.0001$ \\
$\begin{array}{l}\text { Mean total charge of hospitalization } \\
\quad(\text { mean, SD) }\end{array}$ & $63,120.2$ & $60,210.1$ & $2986.61(-77.41$, & 0.056 \\
Hepatorenal syndrome & $(86,257.3)$ & $(105,491.5)$ & $6050.64)$ & \\
Ascites & $121(1.6 \%)$ & $5(0.1 \%)$ & $\mathbf{2 4 . 8 4 ( 1 0 . 1 5 , 6 0 . 8 3 )}$ & $<0.0001$ \\
Variceal bleeding & $2438(32.2 \%)$ & $120(1.6 \%)$ & $\mathbf{3 0 . 2}(\mathbf{2 5 . 0 4 , 3 6 . 4 3})$ & $<0.0001$ \\
Hepatic encephalopathy & $717(9.5 \%)$ & $141(1.9 \%)$ & $\mathbf{5 . 5 7}(\mathbf{4 . 6 3}, \mathbf{6 . 7})$ & $<0.0001$ \\
Portal hypertension & $14(0.2 \%)$ & $1(0.0 \%)$ & $\mathbf{1 3 . 8 5}(\mathbf{1 . 8 2}, \mathbf{1 0 5 . 6 5})$ & 0.011 \\
\hline
\end{tabular}

The bold values are the statistically significant values with $p<0.05$

hypertension, pulmonary or peripheral edema, continued or worsening HF, ascites, HRS, and cardiorenal syndrome [11, 13]. Offsetting disease mechanisms create a quasi-stable state in the patient population we studied (ADHF with cirrhosis), but chronic utilization of these mechanisms causes an increased cardiac preload, increased cardiac afterload, increased myocardial workload, and decreased myocardial relaxation. Patients with liver cirrhosis additionally develop cardiomyopathy with abnormal ventricular function initiated by stress, while HF patients have mild alterations of liver function tests, ischemic hepatitis, and cardiac cirrhosis [14]. Both diseases are intertwined and linked by changes to cardiac output and effective arterial blood volume. Our study data highlight the importance of closer surveillance, screening, and better management strategies for patients with ADHF and cirrhosis due to their complex pathophysiological relationship. There needs to be further analysis of subgroups for ADHF and cirrhosis, such as New York Heart Association (NYHA) class, the degree of liver fibrosis, and how these subgroups impact outcomes.

It has been well documented that patients with cirrhosis-related complications have increased mortality, but this was not quantified in terms of objective metrics such as hospital LOS, hospital readmission percentage and rate, or the exact total hospital charges costs associated with each complication [19]. The impact of each complication on mortality and healthcare utilization is still unknown with limited evidence. A recent literature review in the New England Journal of Medicine showed that patients with cirrhosis and ascites died within 1 year, $44 \%$ died within 5 years, and $5 \%$ of patients with cirrhosis developed hepatocellular carcinoma, with the medical survival and survived approximately 6 months to 2 years [19]. Our study concretely shows that mortality, hospital LOS, and total hospital charges are dramatically increased when there is decompensated cirrhosis with complications.

The primary independent negative driver of mortality was Hispanic ethnicity, but this group was simultaneously an independent positive driver for hospital LOS and total hospital charges. Hispanic patients, the largest minority group in the United States, had $42 \%$ less mortality compared to other groups in our study. Vivo et al. showed that Hispanic patients have excessive rates of cardiovascular comorbidities and therefore they have an increased risk of developing ADHF [15]. Other studies have shown that Hispanic patients have less cardiovascular mortality than other minorities, but they continue to have significant morbidity, like high total hospital charges [16]. Kim et al. additionally identify the Hispanic population as 
Table 3 ADHF with cirrhosis: association of gender, race, payment type, and outcomes (mortality, length of stay, and total charge of hospitalization)

\begin{tabular}{|c|c|c|c|c|c|c|}
\hline \multirow[t]{2}{*}{ Demographics } & \multicolumn{2}{|l|}{ Mortality } & \multicolumn{2}{|l|}{ Length of stay } & \multicolumn{2}{|l|}{ Total charge of hospitalization } \\
\hline & OR (95\% CI) & $p$ value & Beta $(95 \% \mathrm{CI})$ & $p$ value & Beta $(95 \% \mathrm{CI})$ & $p$ value \\
\hline \multicolumn{7}{|l|}{ Gender } \\
\hline Female & 1 & Reference & 1 & Reference & 1 & Reference \\
\hline Male & $\begin{array}{l}1.22(0.94 \\
1.59)\end{array}$ & 0.14 & $\begin{array}{l}0.06(-0.24 \\
0.37)\end{array}$ & 0.67 & $3468.74(-558.27,7495.76)$ & 0.091 \\
\hline \multicolumn{7}{|l|}{ Race/ethnicity } \\
\hline $\begin{array}{l}\text { Non-Hispanic } \\
\text { White }\end{array}$ & 1 & Reference & 1 & Reference & 1 & Reference \\
\hline $\begin{array}{l}\text { African } \\
\text { American }\end{array}$ & $\begin{array}{l}0.76(0.51 \\
1.13)\end{array}$ & 0.17 & $\begin{array}{l}0.18(-0.24 \\
0.59)\end{array}$ & 0.39 & $\begin{array}{l}2212.94(-3273.77 \\
7699.66)\end{array}$ & 0.42 \\
\hline Hispanic & $\begin{array}{l}0.57(0.35 \\
0.91)\end{array}$ & 0.018 & $\begin{array}{l}-0.1(-0.55 \\
0.35)\end{array}$ & 0.66 & $\begin{array}{l}19,072.59(13,102.7 \\
25,042.48)\end{array}$ & $<.0001$ \\
\hline $\begin{array}{l}\text { Asian/Pacific } \\
\text { Islander }\end{array}$ & $\begin{array}{l}1.28(0.59 \\
2.79)\end{array}$ & 0.53 & $\begin{array}{l}0.55(-0.49 \\
1.59)\end{array}$ & 0.31 & $\begin{array}{l}25,518.01(11,714.87, \\
39,321.16)\end{array}$ & 0.0003 \\
\hline Native American & $\begin{array}{l}1.12(0.27 \\
4.68)\end{array}$ & 0.87 & $\begin{array}{l}-0.18(-1.81 \\
1.46)\end{array}$ & 0.83 & $\begin{array}{l}-7544.96(-29,209.9 \\
14,119.97)\end{array}$ & 0.49 \\
\hline \multicolumn{7}{|l|}{ Primary insurance } \\
\hline Private/HMP & 1 & Reference & 1 & Reference & 1 & Reference \\
\hline Medicare & $0.69(0.47,1)$ & 0.051 & $1.58(0.68,2.48)$ & 0.0006 & $\begin{array}{l}-6902.92(-13,058.46 \\
-747.37)\end{array}$ & 0.028 \\
\hline Medicaid & $\begin{array}{l}0.63(0.36 \\
1.07)\end{array}$ & 0.087 & 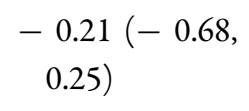 & 0.36 & $\begin{array}{l}-138.98(-7469.23 \\
7191.27)\end{array}$ & 0.97 \\
\hline Self-pay & $\begin{array}{l}0.82(0.34 \\
1.98)\end{array}$ & 0.65 & $\begin{array}{l}0.19(-0.36 \\
0.75)\end{array}$ & 0.49 & $\begin{array}{l}-2154(-14,236.19, \\
9928.19)\end{array}$ & 0.72 \\
\hline No-charge & NA & NA & $\begin{array}{l}-0.32(-1.23, \\
0.59)\end{array}$ & 0.49 & $\begin{array}{l}301.19(-44,966.75 \\
\quad 45,569.14)\end{array}$ & 0.98 \\
\hline Other & $\begin{array}{l}0.13(0.02 \\
0.95)\end{array}$ & 0.044 & $\begin{array}{r}-1.53(-4.95, \\
1.89)\end{array}$ & 0.37 & $\begin{array}{l}1674.25(-12,362 \\
15,710.49)\end{array}$ & 0.81 \\
\hline $\begin{array}{l}\text { Hepatorenal } \\
\text { syndrome }\end{array}$ & $\begin{array}{l}3.38(1.85 \\
6.18)\end{array}$ & 0.00008 & $2.35(1.18,3.51)$ & $<.0001$ & $\begin{array}{l}21,547.6(6100.86 \\
36,994.35)\end{array}$ & 0.0063 \\
\hline Ascites & $\begin{array}{l}1.46(1.12 \\
1.89)\end{array}$ & 0.0051 & $1.29(0.97,1.61)$ & $<.0001$ & $5376.21(1151.6,9600.82)$ & 0.012 \\
\hline Variceal bleeding & $1.34(0.89,2)$ & 0.15 & $\begin{array}{l}0.43(-0.08 \\
0.95)\end{array}$ & 0.097 & $\begin{array}{c}6109.17(-683.96 \\
12,902.3)\end{array}$ & 0.078 \\
\hline
\end{tabular}


Table 3 continued

\begin{tabular}{|c|c|c|c|c|c|c|}
\hline \multirow[t]{2}{*}{ Demographics } & \multicolumn{2}{|l|}{ Mortality } & \multicolumn{2}{|l|}{ Length of stay } & \multicolumn{2}{|c|}{ Total charge of hospitalization } \\
\hline & OR $(95 \% \mathrm{CI})$ & $p$ value & Beta $(95 \% \mathrm{CI})$ & $p$ value & Beta $(95 \% \mathrm{CI})$ & $p$ value \\
\hline $\begin{array}{l}\text { Hepatic } \\
\text { encelopathy }\end{array}$ & $\begin{array}{l}4.73(1.02 \\
21.93)\end{array}$ & 0.047 & $2.5(-0.89,5.9)$ & 0.14 & $\begin{array}{l}51,113.29(6162.68 \\
96,063.9)\end{array}$ & 0.025 \\
\hline $\begin{array}{l}\text { Portal } \\
\text { hypertension }\end{array}$ & $\begin{array}{c}0.65(0.43 \\
0.98)\end{array}$ & 0.039 & $0.76(0.32,1.2)$ & 0.0007 & $5733(-96.29,11,562.3)$ & 0.053 \\
\hline
\end{tabular}

particularly at risk for chronic liver disease. Both of these studies emphasize the value of our study. It unifies these two high-burden diseases and provides an analysis of the resulting outcomes on the Hispanic population [17]. We hypothesize that mortality was decreased in the Hispanic population due to the longer hospital LOS and higher hospital charges incurred. There are still many barriers to eliminating healthcare disparities for Hispanic patients because most of these patients have no health insurance, poor access to vital medical interventions that directly affect hospital LOS and QoL, or poor health insurance coverage. All of these factors could explain the longer hospital LOS and higher total hospital charges [15]. This patient population needs to be better supported with social, health, and human services after discharge; earlier recruitment of case management in the hospital; and early involvement of cardiologists and hepatologists to decrease their hospital LOS and total hospital charges. These early interventions may further decrease mortality for patients with ADHF and cirrhosis in this patient population.

Furthermore, Medicare insurance was identified as an independent positive driver of both hospital LOS and hospital charges. Previous studies have shown that heart failure patients with private insurance have 9\% less hospital length of stay compared to patients with Medicare [10]. Patients with Medicare may not have access to the best treatment options due to higher costs when compared to patients with private insurance, which can provide more benefits. Our patients with Medicare had a 1.58 times higher hospital LOS. This increased hospital LOS is directly correlated to increased healthcare costs. Previous HF studies reveal that hospital LOS, patient demographics, and payer groups have a statistically significant impact on readmissions and mortality rates [1]. It would likely be beneficial for patients with Medicare to have support from social work earlier in their hospital stay to help identify socio-economic factors which could be contributing to increased readmission rates. Furthermore, personalized support after discharge can greatly assist our patient population: programs for maintenance and compliance with appointment schedules, language-services that advise, inform, and educate them on living with and successfully navigating the burden of these two diseases, and adequate psychological, social, and emotional support. All of these interventions will ultimately help decrease their hospital LOS, total hospital charges, and reduce overall mortality as a result.

\section{Limitations}

Our study had several limitations. We analyzed NIS data from the year 2016. This is one of the most recent years that has been currently released and that we can currently access. We maintain a cautious awareness of the fact that our data are representative of a single year and acknowledge that it limits our ability to extrapolate. Since NIS is a discharge-level database, it does not account for repeat admissions 
as patient identifiers are not included. The NIS dataset also does not provide laboratory data or account for treatments with diuretics such as furosemide, spironolactone, combination medications (sacubitril/enalapril), beta blockers, and other therapies such as albumin, terlipressin, vasoactive agents and midodrine. We did not sub-categorize the type of HF, such as HFpEF, HFrEF, diastolic dysfunction, or systolic dysfunction, because we wanted to examine patients with ADHF specifically. We were not able to assess the degree of cirrhosis or advancement of liver disease, which is known in the literature to play a significant role in disease prognosis and interaction with other organs. The NIS database utilizes ICD-10 codes for diagnoses, which limits quantification of the degree of fibrosis for the patients diagnosed with cirrhosis. For hyperaldosteronism seen in patients with cirrhosis, the degree of cirrhosis is the most important indicator and part of the underlying pathophysiology of ADHF. We were not able to examine this important relationship with our current data set secondary to the limitations of the inherent design of the database. Despite extensive searches in the literature, we were not able to find studies that were able to draw significant conclusions on the relationship between these two highly prevalent issues in medicine today. Individually, there is a significantly higher number of studies on HF and its complications with regards to our parameters, but not for cirrhosis. In the literature, the interaction between these two diseases is approached from different angles, but despite the tangible link, there was no cohesive pattern that emerged. Long-term outcomes post-hospitalization were also unaccounted for as the database only allows for analysis of data ranging from admission to discharge. The results may not be generalizable to international populations despite a broad spectrum of localities represented within the weighted data. We acknowledge that both HF and liver disease are a significant issue worldwide, and as such, believe that an analysis of our study parameters internationally would shed additional light on this growing concern.

\section{CONCLUSIONS}

In conclusion, we found that patients with ADHF and cirrhosis have higher mortality and hospital LOS. Our findings, using multivariate logistic regression with propensity matched analysis to remove confounders, suggest that patients with ADHF and cirrhosis had up to a two-fold increase in mortality and 1.2-fold increase in hospital LOS except for the Hispanic population. We found the paucity of data analyzing both ADHF and cirrhosis to be particularly glaring. Current management mostly revolves around supportive care. Yet timely screening to risk stratify at risk populations, such as liver transplantation, heart catheterization, and TIPS procedures, with echocardiography and cardiac magnetic resonance imaging, will be crucial to improving outcomes. Rapidly developing research for exciting and novel interventions, such as albumin plasma volume expansion and ivabradine on cardiac function, are promising. It is of paramount importance that clinicians, administrators, and patients themselves are aware of the toll these two diseases can take if the relationship is not identified early in the disease processes.

\section{ACKNOWLEDGEMENTS}

Funding. No funding or sponsorship was received for this study or publication of this article. The Rapid Service Fee was funded by the authors.

Authorship. All named authors meet the International Committee of Medical Journal Editors (ICMJE) criteria for authorship for this article, take responsibility for the integrity of the work as a whole, and have given their approval for this version to be published.

Disclosures. Yaser S. Khalid, Debashis Reja, Neethi R. Dasu, Herman P. Suga, Kirti N. Dasu, and Lucy M. Joo have nothing to disclose.

Compliance with Ethics Guidelines. Ethics committee approval was not required because 
the NIS data used in this study was fully deidentified and therefore was considered exempt from institutional review board approval. The datasets are publicly available in the NIS 2016 data repository at https://www.hcup-us.ahrq. gov/databases.jsp.

Data Availability. The datasets generated during and/or analyzed during the current study are available in the NIS 2016 data repository, https://www.hcup-us.ahrq.gov/databases. jsp.

Open Access. This article is licensed under a Creative Commons Attribution-NonCommercial 4.0 International License, which permits any non-commercial use, sharing, adaptation, distribution and reproduction in any medium or format, as long as you give appropriate credit to the original author(s) and the source, provide a link to the Creative Commons licence, and indicate if changes were made. The images or other third party material in this article are included in the article's Creative Commons licence, unless indicated otherwise in a credit line to the material. If material is not included in the article's Creative Commons licence and your intended use is not permitted by statutory regulation or exceeds the permitted use, you will need to obtain permission directly from the copyright holder. To view a copy of this licence, visit http://creativecommons.org/licenses/by$\mathrm{nc} / 4.0 /$.

\section{REFERENCES}

1. Allen LA, Smoyer Tomic KE, Wilson KL, Smith DM, Agodoa I. The inpatient experience and predictors of length of stay for patients hospitalized with systolic heart failure: comparison by commercial, Medicaid, and Medicare payer type. J Med Econ. 2013;16(1):43-544.

2. Mirkin KA, Enomoto LM, Caputo GM, Hollenbeak CS. Risk factors for 30-day readmission in patients with congestive heart failure. Heart Lung. 2017;46(5):357-62.

3. Lee SS, Liu H. Cardiovascular determinants of survival in cirrhosis. Gut. 2007;56(6):746-8.
4. Chirapongsathorn S, Poovorawan K, Soonthornworasiri N, Pan-ngum W, Phaosawasdi K, Treeprasertsuk $S$. Thirty-day readmission and cost analysis in patients with cirrhosis: a nationwide population-based data. Hepatol Commun. 2020;4(3):453-60.

5. Fede G, Privitera G, Tomaselli T, Spadaro L, Purrello F. Cardiovascular dysfunction in patients with liver cirrhosis. Ann Gastroenterol Q Publ Hell Soc Gastroenterol. 2015;28(1):31-40.

6. Valbusa F, Bonapace S, Agnoletti D, Scala L, Grillo C, Arduini P, et al. Nonalcoholic fatty liver disease and increased risk of 1-year all-cause and cardiac hospital readmissions in elderly patients admitted for acute heart failure. PLoS ONE [Internet]. 2017 Mar 13 [cited 2020 May 5];12(3). https://www.ncbi. nlm.nih.gov/pmc/articles/PMC5348001/

7. Sud M, Yu B, Wijeysundera HC, Austin PC, Ko DT, Braga J, et al. Associations between short or long length of stay and 30-day readmission and mortality in hospitalized patients with heart failure. JACC Heart Fail. 2017;5(8):578-88.

8. Pandey A, Omar W, Ayers C, LaMonte M, Klein L, Allen $\mathrm{N}$, et al. Sex and race differences in lifetime risk of heart failure with preserved ejection fraction and heart failure with reduced ejection fraction. Circulation. 2018;137(17):1814-23.

9. Desai AP, Mohan P, Nokes B, Sheth D, Knapp S, Boustani $\mathrm{M}$, et al. Increasing economic burden in hospitalized patients with cirrhosis: analysis of a national database. Clin Transl Gastroenterol. 2019;10(7):e00062.

10. Joshi AV, D'Souza AO, Madhavan SS. Differences in hospital length-of-stay, charges, and mortality in congestive heart failure patients. Congest Heart Fail. 2004;10(2):76-84.

11. Bansal S, Lindenfeld J, Schrier RW. Sodium retention in heart failure and cirrhosis: potential role of natriuretic doses of mineralocorticoid antagonist? Circ Heart Fail. 2009;2(4):370-6.

12. Schrier RW. Decreased effective blood volume in edematous disorders: what does this mean? J Am Soc Nephrol. 2007;18(7):2028-31.

13. Schrier RW. Use of diuretics in heart failure and cirrhosis. Semin Nephrol. 2011;31(6):503-12.

14. Hsu R-B, Chang C-I, Lin F-Y, Chou N-K, Chi N-H, Wang S-S, et al. Heart transplantation in patients with liver cirrhosis. Eur J Cardiothorac Surg. 2008;34(2):307-12. 
15. Vivo RP, Krim SR, Cevik C, Witteles RM. Heart failure in Hispanics. J Am Coll Cardiol. 2009;53(14): 1167-75.

16. Miles JA, Quispe R, Mehlman Y, Patel K, Lama Von Buchwald C, You JY, et al. Racial differences and mortality risk in patients with heart failure and hyponatremia. PLoS ONE [Internet]. 2019 Jun 19 [cited 2020 May 9];14(6). https://www.ncbi.nlm. nih.gov/pmc/articles/PMC6583993/.

17. Kim D, Li AA, Perumpail RB, Cholankeril G, Gonzalez SA, Kim W, et al. Disparate trends in mortality of etiology-specific chronic liver disease among Hispanic subpopulations. Clin Gastroenterol
Hepatol Off Clin Pract J Am Gastroenterol Assoc. 2019;17(8):1607-1615.e2.

18. Powell EE, Skoien R, Rahman T, Clark PJ, O'Beirne J, Hartel G, et al. Increasing hospitalization rates for cirrhosis: overrepresentation of disadvantaged Australians. EClinicalMedicine. 2019;11:44-53.

19. Krill T, Brown G, Weideman RA, Cipher DJ, Spechler SJ, Brilakis E, et al. Patients with cirrhosis who have coronary artery disease treated with cardiac stents have high rates of gastrointestinal bleeding, but no increased mortality. Aliment Pharmacol Ther. 2017;46(2):183-92. 